\title{
Assessment of emissions data for the Toronto region using aircraft-based measurements and an air quality model
}

\author{
D.A. Plummer ${ }^{\mathrm{a}, *}$, J.C. McConnell ${ }^{\mathrm{a}}$, L. Neary ${ }^{\mathrm{a}}, \mathrm{J}$. Kominski ${ }^{\mathrm{a}}$, R. Benoit ${ }^{\mathrm{b}}$,

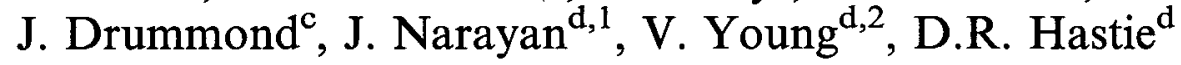 \\ ${ }^{a}$ Centre for Research in Earth and Space Science, York University, Toronto, Ont., Canada M3J 1P3 \\ ${ }^{\mathrm{b}}$ Recherche en Prevision Numerique, Environment Canada, 2121 Trans-Canada N., Suite 564, Dorval, Quebec, Canada, H9P $1 J 3$ \\ ${ }^{c}$ Unisearch Associates Inc., 96 Bradwick Dr., Concord, Ont., Canada L4K IK8 \\ ${ }^{\mathrm{d}}$ Centre for Atmospheric Chemistry, York University, Toronto, Ont., Canada M3J 1 P3
}

Received 14 March 2001; received in revised form 13 August 2001; accepted 24 August 2001

\begin{abstract}
An aircraft-based measurement campaign was conducted during the summer of 1996 in the vicinity of Toronto, Canada. The objective of the campaign was to assess the errors in a particular emission inventory used by threedimensional air quality models. Measurements of $\mathrm{NO}_{2}$ and hydrocarbons were made both upwind and downwind of Toronto, on days with strong synoptic-scale flow from a west to northerly direction. The chemical composition of the background airmass on these days was typical of unpolluted continental air. Measurements have been compared with the output from an on-line air quality model (MC2-AQ) run at $5 \mathrm{~km}$ resolution and suggest that emissions of $\mathrm{NO}_{x}$ from Toronto are well described in the emission database, though evidence that $\mathrm{NO}_{x}$ emissions are underestimated for suburban regions surrounding Toronto was found. In general, no significant underestimation of hydrocarbon emissions was found, though emissions of the model propane species, which includes acetylene and benzene, was underestimated by at least a factor of two.
\end{abstract}

Keywords: Emission inventory; Regional air quality; Modelling; Canada; Ontario; Toronto

\section{Introduction}

Emissions-based, regional-scale models are currently used to assess the effects of various hydrocarbon and $\mathrm{NO}_{x}$ emission control strategies on ozone concentrations (e.g. $\mathrm{NO}_{x} /$ VOC-SP, 1997). These models calculate the effects of chemical and physical processes on trace species distributions and require as input, spatially and temporally distributed estimates of the emission of hydrocarbons and $\mathrm{NO}_{x}$. If models are to correctly predict the response of the system to reductions in the

\footnotetext{
*Corresponding author.

E-mail address: plummer@nimbus.yorku.ca (D.A. Plummer).

${ }^{1}$ Now at the Meteorological Service of Canada, Toronto, Ontario.

${ }^{2}$ Now at Ohio University, Athens, Ohio.
}

emission of $\mathrm{NO}_{x}$ and hydrocarbons, the emissions data used within these models must be as accurate as possible. However, emission inventories are one of the more uncertain components of air quality models.

Indications that emissions inventories may contain significant errors were first noted from comparisons of ambient $\mathrm{CO} / \mathrm{NO}_{x}$ and hydrocarbon/ $\mathrm{NO}_{x}$, or $\mathrm{HC} / \mathrm{NO}_{x}$, ratios observed in city centres with the ratios found in emissions inventories (Ching et al., 1987; Fujita et al., 1992). These studies suggested that hydrocarbon emissions may be underestimated by as much as a factor of four. Observations of motor-vehicle emissions taken in a roadway tunnel in California added further support, showing both the absolute hydrocarbon emissions and the $\mathrm{HC} / \mathrm{NO}_{x}$ ratios were underestimated by the mobile emissions model by a factor of between 3 and 4 (Pierson et al., 1990). More recent roadway tunnel studies in the Northeastern US have found considerably better 
agreement between observed and predicted emissions of hydrocarbons (Pierson et al., 1996).

In general, roadway tunnel studies have found adequate agreement between predictions and observations for the absolute amount of $\mathrm{NO}_{x}$ emissions from motor-vehicles (Pierson et al., 1990, 1996).

Though roadway tunnel studies are capable of providing estimates of actual emission rates, these studies are only applicable to motor-vehicle emissions. Observations of ambient $\mathrm{CO}$, hydrocarbon and $\mathrm{NO}_{x}$, or $\mathrm{NO}_{y}$, concentrations in cities capture emissions from a wider range of sources and provide information on the ratios between emitted species. If it is assumed that these species have not had sufficient time to react, the observed ratios can then be compared with ratios found in the emissions inventories, though due to the unknown effects of dispersion the observations of ambient concentrations cannot be related to actual emission fluxes.

One method that has been used to derive estimates of actual emission rates from a city as a whole has been the mass-balance approach. An estimate of the $\mathrm{NO}_{x}$ emissions for Birmingham, Alabama was made by Trainer et al. (1995) using such an approach. Aircraft observations of $\mathrm{NO}_{y}$ were made upwind and downwind of the city and a two-dimensional distribution of $\mathrm{NO}_{y}$ was created from the observations, assuming that the $\mathrm{NO}_{y}$ concentration did not vary with height over the depth of the boundary layer. An average boundary layer wind vector was calculated from the aircraft observed winds and fluxes of $\mathrm{NO}_{y}$ upwind and downwind of the city were calculated, with emissions from Birmingham accounting for the difference. Agreement between the observed emissions and that given by the 1985 National Acid Precipitation Assessment Program (NAPAP) emission inventory was found, within a given factor of two uncertainty, for each of the five days studied.

In an attempt to improve on the mass-balance approach, the study presented here compares aircraft observations made upwind and downwind of Toronto, Canada with the output from a three-dimensional air quality model. A comparison of the observed species concentrations downwind of Toronto with the model calculated concentrations is performed and the results are extrapolated to provide an assessment of the emissions data used in the model.

\section{Description of the study}

As part of the Southern Ontorio Oxidant Study (SONTOS), aircraft flights were conducted on three days, the 18, 24 and 29 August 1996, under meteorological conditions where the synoptic flow was from a northerly or northwesterly direction. Under these conditions, Toronto, situated along the northern edge of the industrialized regions of eastern North America, receives relatively unpolluted air. The study days were chosen to maximize the effect of Toronto area emissions on the concentrations of $\mathrm{NO}_{x}$ and hydrocarbons downwind of the city, by choosing days when the concentration of these species in the upwind airmass could be expected to be the lowest. The study days were also chosen so that the meteorological conditions under which pollutants emitted from Toronto are advected and dispersed downwind are relatively uncomplicated.

On each of the measurement days an aircraft flight was made during the late morning and early afternoon, which was comprised of several transects at different altitudes and approximately perpendicular to the synoptic flow, between 40 and $60 \mathrm{~km}$ upwind of Toronto. A complimentary flight was made in the late afternoon just south of Toronto and parallel to the lakeshore. The path of the flights was designed to characterize the concentrations of hydrocarbons and $\mathrm{NO}_{x}$ in the airmass upwind of Toronto and in the Toronto plume just downwind of the city. An example of the flight pattern is given in Fig. 1, which presents the aircraft flight path and the location of hydrocarbon samples for the flight on 18 August. Also shown in Fig. 1, is the anthropogenic area emission field of NO used in the model, which is discussed further below.

During both the upwind and downwind flights, $\mathrm{O}_{3}$, $\mathrm{NO}_{2}$ and $\mathrm{NO}_{x}$ were continuously measured and between 5 and 10 hydrocarbon samples were collected in stainless steel canisters for later analysis. Air was sampled from a point $80 \mathrm{~cm}$ aft of the nose of the aircraft and $15 \mathrm{~cm}$

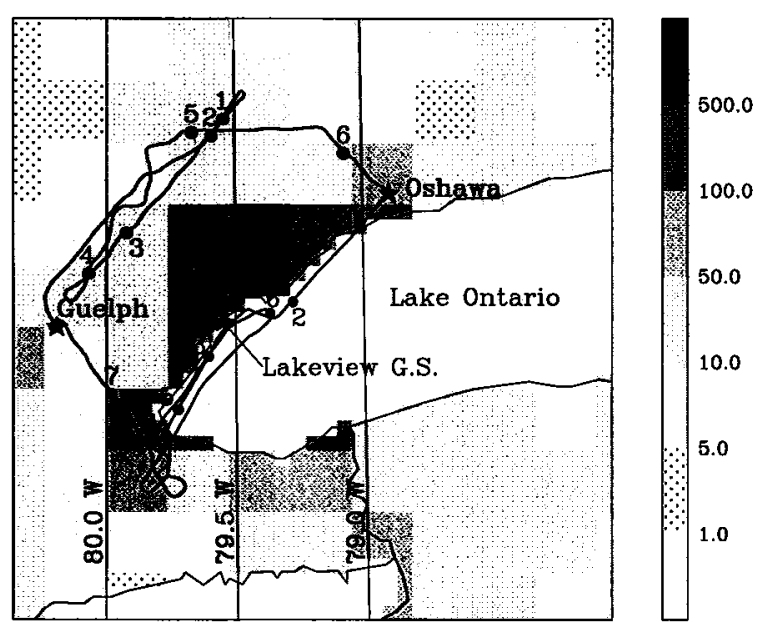

Fig. 1. The spatial distribution of area emissions of NO for a generic summer weekday at 1600 EDT. The emission field has a horizontal resolution of $5.3 \times 5.3 \mathrm{~km}^{2}$ and are given in units of $10^{12}$ molecules $\mathrm{cm}^{-2} \mathrm{~s}^{-1}$. Also shown is the aircraft flight path for 18 August, 1996, with the location where hydrocarbon samples were taken given by the numbered points along the flight path. Separate numbering is used for the upwind and downwind of Toronto flights. 
from the fuselage, through individual $6.3 \mathrm{~mm}$ tubes oriented perpendicular to the fuselage. Teflon tubing was used for the analysers and stainless steel for the hydrocarbon sampling. Ozone was measured using a LOZ-3 $\mathrm{O}_{3}$ (Eosin-y) analyser. The LOZ-3 data are corrected for pressure and temperature by the instrument itself. The LOZ-3 $\mathrm{O}_{3}$ was calibrated before and after each flight by comparison to a Dasibi model 1003AH ozone monitor. The $\mathrm{NO}_{2}$ and $\mathrm{NO}_{x}$ measurements were made using two LMA-3 $\mathrm{NO}_{2}$ luminol-based analysers, one which measured $\mathrm{NO}_{2}$ directly and one which sampled the air via a Permapur Nafion drier and a $\mathrm{CrO}_{3} \mathrm{NO}$ to $\mathrm{NO}_{2}$ converter (Drummond et al., 1990). The LMA-3 data were corrected for ambient pressure and non-linearity as described in Drummond et al. (1990). The LMA-3's were calibrated and zero checked before, after and during each flight by an on-board permeation tube calibration system. The instruments were also audited by the Ontario Ministry of the Environment and Energy audit group, both before and after the flight campaign, and no anomalies were observed. Air temperature was measured using a thermistor located at the sample inlet, ambient pressure using a Sensym LX1602A and aircraft position by a Rockwell International model NavCorV GPS. Altitude was determined by the average of the GPS altitude and the on-board pressure-altitude sensor.

To assess the emissions inventory for the Toronto region, the aircraft measurements have been compared to the concentrations predicted by a three-dimensional air quality model, MC2-AQ (Plummer, 1999), which is a mesoscale model with an on-line chemical module including gas-phase chemistry, dry deposition and anthropogenic and biogenic emissions. The MC2-AQ model developed from a preexisting non-hydrostatic meteorological model known as MC2 (Benoit et al., 1997) and uses the same model grid and advection algorithm as the original MC2 model. The model has been run in a nested manner, with the finest horizontal resolution being approximately $5 \mathrm{~km}$, for the three days when aircraft flights were made. By comparing the hydrocarbon and $\mathrm{NO}_{x}$ concentrations observed just downwind of Toronto with the model calculated concentrations, an estimate of the accuracy of the emissions inventory used in the model was developed.

\subsection{Methodology}

The MC2-AQ model has been run at a horizontal resolution of approximately $5 \mathrm{~km}$ for each of the three days when measurements were made. To achieve the high resolution simulations, a set of nested runs were made using one-way nesting to pass boundary conditions to the progressively higher resolution runs. An initial model run at a horizontal resolution of $42 \mathrm{~km}$, on a domain covering most of eastern North America, was used to provide initial and boundary conditions for a $21 \mathrm{~km}$ resolution model run on a $2000 \mathrm{~km} \times 2000 \mathrm{~km}$ domain that covered the North-eastern US and adjacent regions of Southern Canada. Subsequently, the $5.3 \mathrm{~km}$ resolution model run was performed on a $450 \mathrm{~km} \times$ $450 \mathrm{~km}$ domain centred around Toronto, beginning at 0000 GMT on the day of the aircraft flight. Further details of the way in which the set of nested runs was created can be found in Plummer (1999).

In a typical application of the MC2-AQ model, chemistry would be calculated for the $21 \mathrm{~km}$ resolution simulation, which would provide spatially and temporally varying boundary conditions for the chemical tracers on the $5.3 \mathrm{~km}$ resolution domain. However, since all three days of the aircraft study were characterized by unpolluted northerly flow, a regional MC2-AQ run to develop chemical boundary conditions for each $5.3 \mathrm{~km}$ resolution run was felt to be unnecessary. Rather, the chemical fields calculated by a $21 \mathrm{~km}$ resolution run of MC2-AQ for 31 July 1988 were used to provide the chemical initial and boundary conditions for the three days of the emissions study. The synoptic conditions on 31 July 1988 were quite similar to those on each of the aircraft measurement days, with northwesterly synoptic flow bringing unpolluted air across southern Ontario. The use of generic 'clean' boundary conditions should not significantly affect the final results.

While the chemical boundary conditions for most species were taken from the $21 \mathrm{~km}$ resolution run for 31 July 1988, an exception was made for hydrocarbons other than isoprene. Since the first flight on each day was made upwind of Toronto to measure the background concentrations in the airmass, the average observed hydrocarbon concentrations made during the upwind flight were used as boundary and initial conditions for the $5.3 \mathrm{~km}$ resolution run. The average observed hydrocarbon concentrations upwind of Toronto were imposed as the boundary condition over the entire model domain and were assumed to be constant with height.

Assessment of the emissions inventory was performed by comparing the observed concentrations of $\mathrm{NO}_{2}$ and hydrocarbons downwind of Toronto with the output from the MC2-AQ model run at $5.3 \mathrm{~km}$ resolution. Due to problems with the $\mathrm{NO}_{x}$ instrument on-board the aircraft, it was not possible to compare the model predictions and observations for $\mathrm{NO}_{x}$.

The hydrocarbon and $\mathrm{NO}_{2}$ observations have been compared to model output by linearly interpolating the model fields in space and time, onto the location of the airplane at each valid observation. The model uses the ADOM chemical mechanism which contains seven emitted non-methane hydrocarbons (NMHCs), in addition to ethane which has a constant mixing ratio. Thus, to perform an intercomparison between the observed and modelled hydrocarbon concentrations it was 
necessary to lump the observed hydrocarbons into the hydrocarbon classes used in the ADOM mechanism. The ADOM hydrocarbon lumping is based on the 32 hydrocarbon class scheme of Middleton et al. (1990), with further aggregation into the final ADOM hydrocarbon species performed using reactivity weighting. Table 1 shows how the individual measured hydrocarbons have been distributed and weighted to derive the ADOM hydrocarbon species.

An important detail to note is that the set of observed hydrocarbons often comprise only a fraction of the variety of different hydrocarbon species represented by the lumped ADOM species. An analysis of the annual emission data for the US contained in the 1980 NAPAP inventory (Middleton et al., 1990) shows that the set of hydrocarbon species measured during the SONTOS 1996 field study account for approximately $70 \%$ (on a molar basis) of the total anthropogenic hydrocarbon emissions in the inventory. Carbonyls, methane and ethane were omitted from this comparison. However, the fraction of hydrocarbons 'missed' by the observations is not evenly distributed amongst the model hydrocarbon species. The model treats ethene explicitly, so a comparison between observations and model calculations is straightforward. Based on the detailed emissions from the 1980 NAPAP inventory, the observed hydrocarbons will represent more than $90 \%$ of the concentration of the total ADOM propane species, due to the large fraction of the model propane

Table 1

Allocation and weighting of the individual hydrocarbon species measured during SONTOS 1996 to derive the lumped hydrocarbon species of the ADOM chemical mechanism

\begin{tabular}{|c|c|}
\hline ADOM species & Measured hydrocarbon \\
\hline $\mathrm{C}_{3} \mathrm{H}_{8}$ & Propane +1.03 Benzene +0.66 Acetylene \\
\hline Lumped alkane & $\begin{array}{l}0.5447\{n \text {-Butane }+i \text {-Butane }+2,2- \\
\text { dimethylpropane }+ \\
\text { 2,2-dimethylbutane }+ \text { cy-Propane }\}+ \\
0.8496\{n \text {-Pentane }+i \text {-Pentane }+n \text {-Hexane }+ \\
\text { 2-me-Pentane }+3 \text {-me-Pentane }+ \\
\text { cy-Pentane }+2,3 \text {-dimethylbutane }\}+ \\
1.2621\{n \text {-Heptane }+ \text { me-cy-Hexane }+ \\
n \text {-Octane }+ \\
n \text {-Nonane }+ \text { cy-Hexane }+ \text { me-cy-Pentane }\}\end{array}$ \\
\hline Ethene & Ethene \\
\hline Lumped alkene & $\begin{array}{l}\text { Propene }+1 \text {-Butene }+i \text {-Butene }+ \\
\text { 1-Pentene }+1,3-\text {-Butadiene }+ \text { trans-2-Butene }+ \\
\text { Cis-2-Butene }+ \text { 1-Hexene }+ \text { trans-2-Pentene }+ \\
\text { 2-me-2-Butene + 2-me-1-Butene + cis-2- } \\
\text { Pentene + } \\
\text { trans-2-Hexene }+ \text { cis-2-Hexene }\end{array}$ \\
\hline Toluene & Toluene + ethyl-Benzene \\
\hline Aromatic & $o$-Xylene $+m$-Xylene $+p$-Xylene \\
\hline Isoprene & Isoprene \\
\hline
\end{tabular}

species accounted for by propane, benzene and acetylene. Observations of species comprising the $\mathrm{ADOM} \geqslant \mathrm{C}_{4}$ alkane species will account for approximately $50 \%$ of the total concentration, due to a large fraction of $\mathrm{C}_{8}$ and larger alkanes, as well as halogenated and oxygenated VOCs, included in the $\geqslant \mathrm{C}_{4}$ alkane species but which were not observed. Approximately $90 \%$ of the lumped $\geqslant \mathrm{C}_{3}$ alkene and $90 \%$ of the model toluene species should be represented by the observed species. Though only $50 \%$ of the model aromatic species should be captured by the observations, due to a significant fraction of di- and tri-alkylbenzenes included in the model aromatic species which are not present in the observations.

Recently, Lewis et al. (2000) have shown that improved chromatographic techniques lead to a dramatically different picture of the absolute amounts and speciation of VOCs in urban air. Conventional chromatography failed to adequately separate many of the $\mathrm{C}_{6}$ and larger VOCs and results, for the examples of urban air presented, in approximately two-thirds of the total VOC mass going unmeasured. The comparison of observed hydrocarbon concentrations with emission data presented here is based on the knowledge of hydrocarbon distributions derived from conventional chromatography and, as such, may require substantial revision in the future.

\subsection{Emissions}

The anthropogenic emissions inventory used for this work is based on the 1985 NAPAP emissions inventory (US EPA, 1989) and, as such, was not specifically developed for the Toronto region or the study period. Rather, the area emissions specified for Toronto are the result of the temporal and spatial reallocation of annual emissions estimates for the province of Ontario as a whole $\left(\mathrm{NO}_{x} /\right.$ VOC-SP, 1997). It should be noted that this inventory was felt to be the best available at the time of this study and has been extensively used for regional modelling studies within the Canadian modelling community.

The original area emissions fields used in this study were on a $21.17 \times 21.17 \mathrm{~km}^{2}$ polar stereographic grid. The urban scale runs of MC2-AQ have been performed at a horizontal resolution exactly one-quarter of the horizontal resolution of the area emissions data. To generate area emissions for use in the fine-scale runs of MC2-AQ, the area emissions were first projected, without interpolation, onto the model grid. The projection of the emissions data onto the finer MC2-AQ grid required some reallocation of emissions to correct for emissions which were projected to lie over bodies of water. The process of correcting for these emissions resulted in a $3 \%$ increase in the area emissions from 
Toronto. Fig. 1 provides an example of the resulting area emission field of NO at a horizontal resolution of $5.29 \mathrm{~km}$.

Also shown on Fig. 1 is the location of the Lakeview Generating Station (G.S.), a $1100 \mathrm{MW}$ coal fired thermal generating station located on the Lake Ontario shoreline just to the west of Toronto. As discussed further below, it appears that the aircraft intercepted the Lakeview G.S. plume on at least two of the three study days.

\section{Comparison for $\mathrm{NO}_{2}$}

Figs. 2-4 present a comparison of the modelled and observed $\mathrm{NO}_{2}$ concentrations for each of the three study days, 18, 24 and 29 August, respectively. Panel (A) of these three figures presents a vertical cross-section of the model calculated $\mathrm{NO}_{2}$ concentration along the aircraft flight path. Panel (B) presents the observed and modelled $\mathrm{NO}_{2}$ concentration as a function of time during the aircraft flight, where model data has been interpolated in space and time onto the aircraft position. Times when the aircraft is believed to have been within the Toronto plume are shown as shaded. A comparison of the observed and modelled $\mathrm{NO}_{2}$ concentration is discussed briefly below for each of the three study days.

\subsection{Sunday 18 August}

Of the three days studied, 18 August was the day with the lightest gradient wind. Observations at Toronto International Airport show winds were from a northerly direction with speeds less than $10 \mathrm{~km} \mathrm{~h}^{-1}$. Calm conditions were frequently reported. Model predictions show the Toronto plume to be centred between $79.2^{\circ}$ and $79.3^{\circ} \mathrm{W}$ and from panel (A) of Fig. 2, it would appear that the aircraft has not well mapped the full horizontal and vertical extent of the Toronto plume.

For the time during which the aircraft was flying through the Toronto plume, shown as the shaded regions of panel (B), instantaneous differences between the modelled and observed $\mathrm{NO}_{2}$ concentrations are frequently as large as $100 \%$ of the observed $\mathrm{NO}_{2}$ concentration. Such a result is not unexpected, since the model will not capture many of the small scale features present in the observations. However, when the average of all $\mathrm{NO}_{2}$ observations taken during the time the aircraft was within the Toronto plume is compared with the average of the spatially and temporally paired model

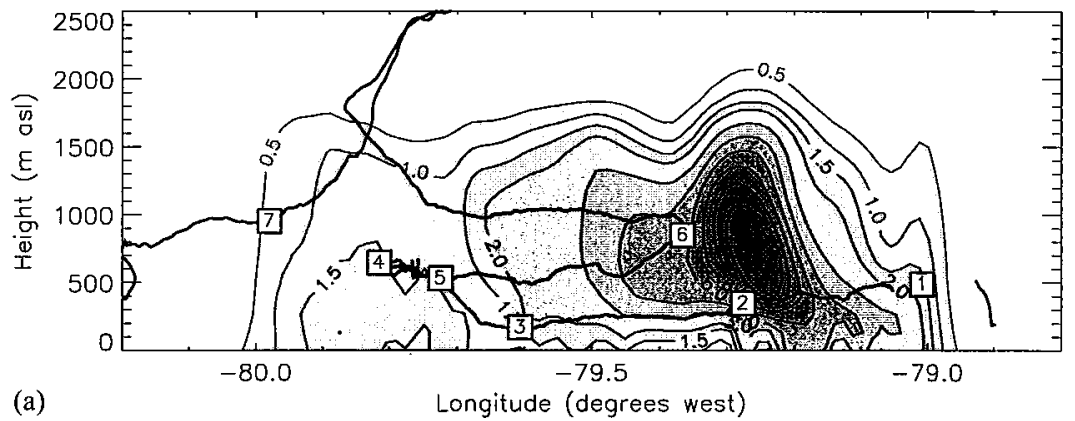

(a)

Longitude (degrees west)

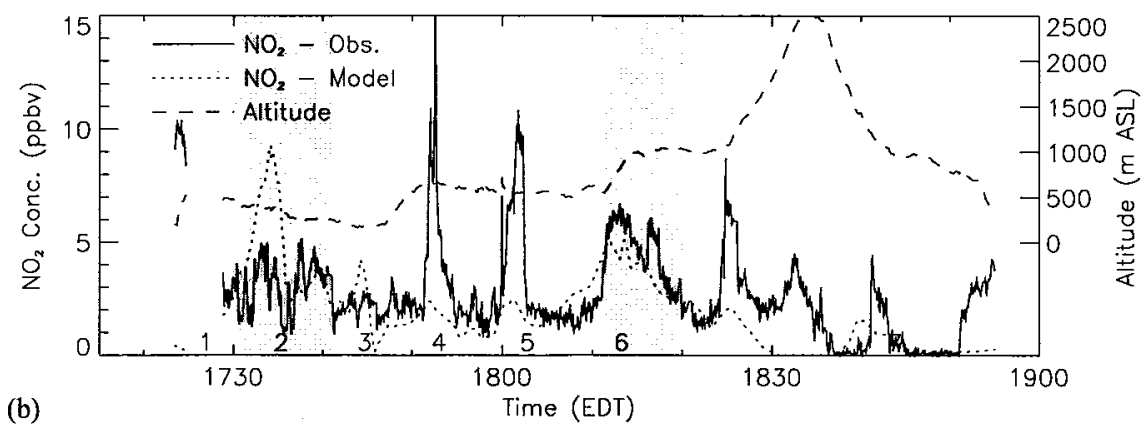

Fig. 2. The observed and model predicted concentration of $\mathrm{NO}_{2}$ for the downwind of Toronto flight on Sunday 18 August 1996 . Panel (A) shows a vertical cross-section of the model predicted $\mathrm{NO}_{2}$ concentration (ppbv) along the flight path, as projected onto a latitude plane. The numbered boxes denote the location at which hydrocarbon samples were taken. Panel (B) shows the observed and model predicted $\mathrm{NO}_{2}$ concentration as a function of time during the flight, with the numbers along the $x$-axis giving the time at which hydrocarbon samples were taken. 


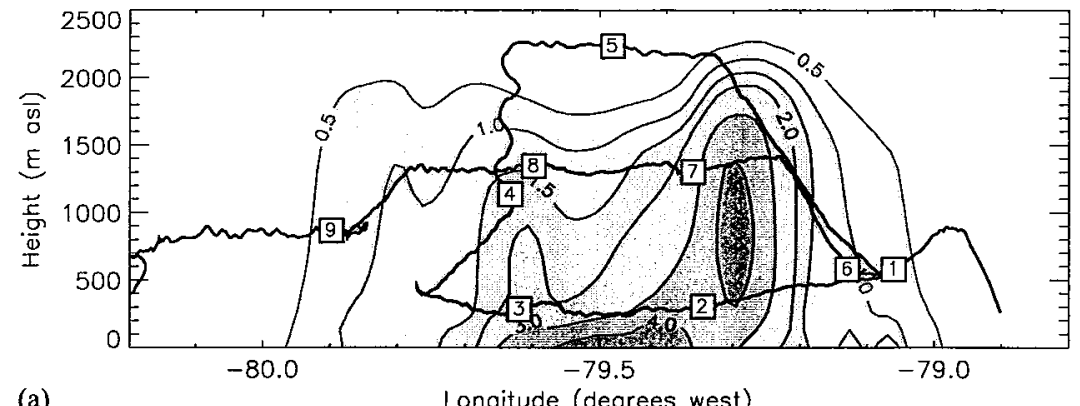

(a)

Longitude (degrees west)

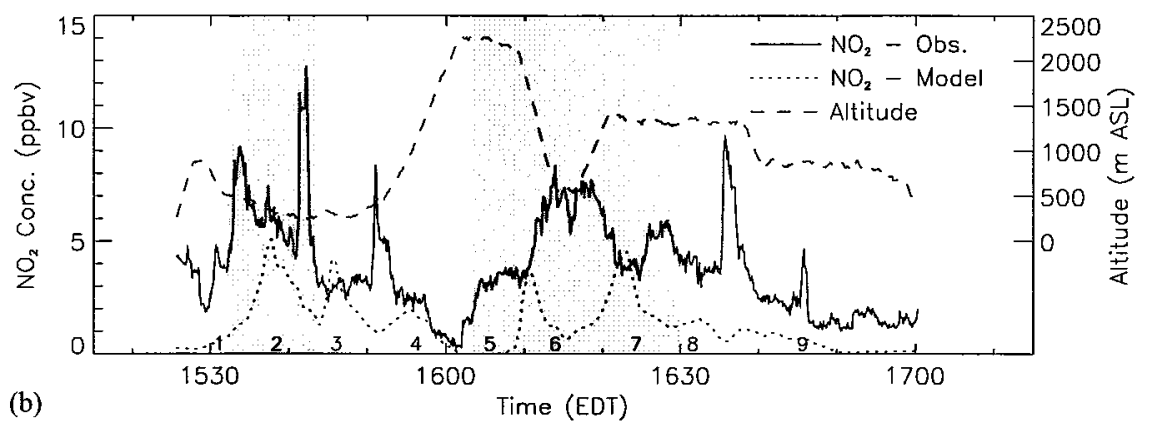

Fig. 3. The observed and model predicted concentration of $\mathrm{NO}_{2}$ (ppbv) for the downwind of Toronto flight on Saturday 24 August 1996. The figure layout is the same as that for Fig. 2.
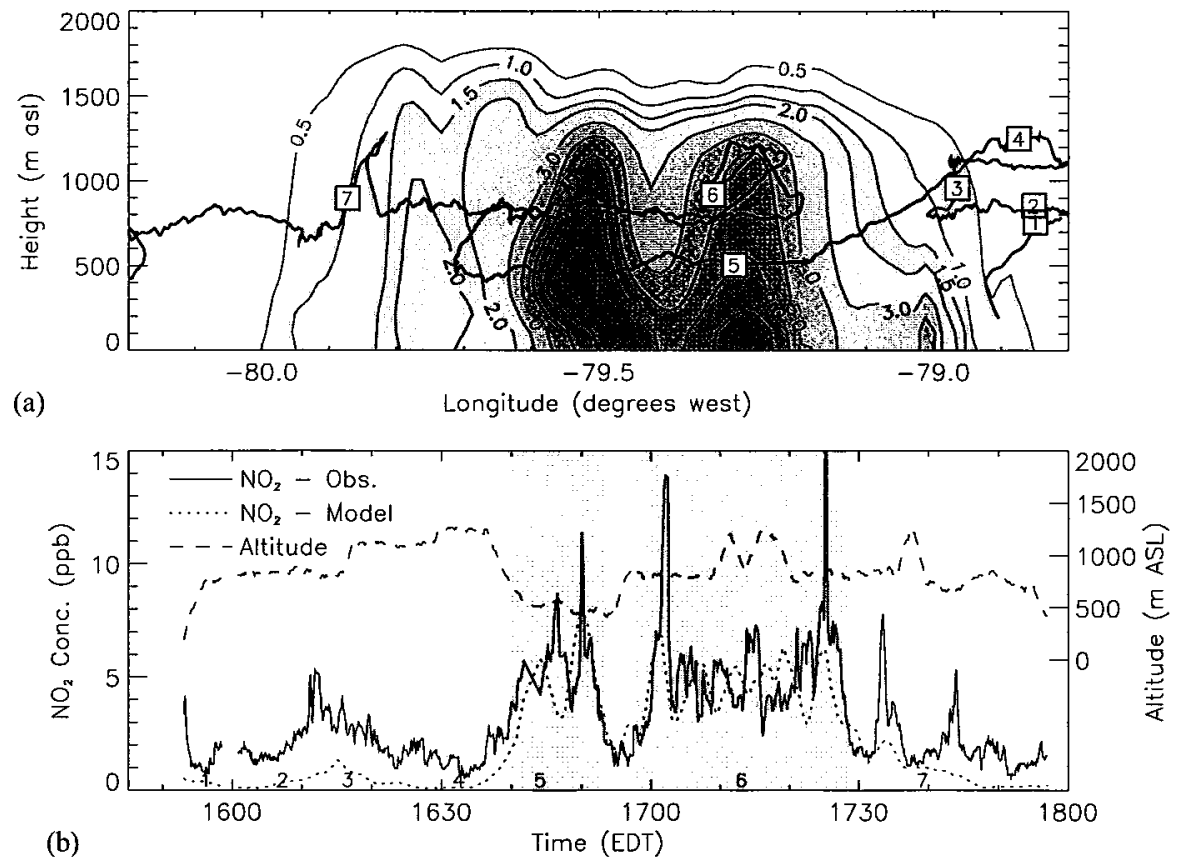

Fig. 4. The observed and model predicted concentration of $\mathrm{NO}_{2}$ (ppbv) for the downwind of Toronto flight on Thursday 29 August 1996. The figure layout is the same as that for Fig. 2.

calculated $\mathrm{NO}_{2}$ concentrations for the same period of time, the results show that the model overpredicts the concentration of $\mathrm{NO}_{2}$ by approximately $12 \%$.
Though the focus of the study was on Toronto, the aircraft flew over and downwind of other urbanized areas surrounding Toronto. In particular, the flight 
passed over the city of Hamilton, with a population of approximately 300000 people and a significant steel making industry, located at the western end of Lake Ontario. For the flight on 18 August, the aircraft passed over Hamilton at approximately 1752, 1801 and 1825 EDT and each time observations show $\mathrm{NO}_{2}$ concentrations of between 5 and $10 \mathrm{ppbv}$, though the model predicted $\mathrm{NO}_{2}$ concentrations never exceeded 3 ppbv. Significant underpredictions of the observed $\mathrm{NO}_{2}$ concentration over the Hamilton region are found for the other two study days as well. These results could indicate problems with the $\mathrm{NO}_{x}$ inventory for Hamilton or could result from artificial spreading of the emissions due to the horizontal resolution of the emissions inventory.

Model predictions also significantly underpredict the $\mathrm{NO}_{2}$ concentration observed to the east of Toronto. As shown in Fig. 2, $\mathrm{NO}_{2}$ concentrations of nearly $10 \mathrm{ppbv}$ were observed shortly after takeoff from Oshawa. Some of the $\mathrm{NO}_{2}$ data during the early portion of the flight is not shown in Fig. 2 due to missing altitude data, though the observations show $\mathrm{NO}_{2}$ concentrations remaining $>5 \mathrm{ppbv}$ up until the time the aircraft moved over the lake. The model predicted $\mathrm{NO}_{2}$ concentrations in the vicinity of Oshawa are generally less than $0.5 \mathrm{ppbv}$.

\subsection{Saturday 24 August}

As can be seen from Fig. 3, differences between model predictions and observations downwind of Toronto on 24 August are considerably larger than those found for 18 August. Model calculations show only a narrow plume downwind of Toronto with $\mathrm{NO}_{2}$ concentrations greater than $4 \mathrm{ppbv}$, though observations indicate a large region over Lake Ontario with $\mathrm{NO}_{2}$ concentrations of between 5 and $8 \mathrm{ppbv}$. Averaged over the time the aircraft was flying through the Toronto plume, the model predicted $\mathrm{NO}_{2}$ concentration was approximately $35 \%$ of the observed concentration.

Surface observations in the vicinity of Toronto show winds were from the north to north-west between 10 and $15 \mathrm{~km} \mathrm{~h}^{-1}$ for much of the day. A comparison of the meteorological observations with model predictions does not suggest any significant errors in the model representation of the meteorology near the surface. Vertical profiles of temperature and $\mathrm{NO}_{2}$ concentration suggest a regional boundary layer depth of approximately $1500 \mathrm{~m}$, though downwind of Toronto the observations suggest a deeper boundary layer with a depth of at least $2000 \mathrm{~m}$ (Oke, 1982). The boundary layer depth predicted by $\mathrm{MC} 2$ is in rough agreement with the observations, though downwind of Toronto the boundary layer depth appears to be underpredicted. Errors in the model representation of the meteorology do not appear to be large enough to account for the factor of three difference between the observed and modelled $\mathrm{NO}_{2}$ concentration in the Toronto plume.

A narrow plume of $\mathrm{NO}_{2}$, with concentrations in excess of $10 \mathrm{ppbv}$, was found at 1541 EDT. As shown earlier in Fig. 1, the Lakeview Generating Station lies almost directly to the north of where the aircraft encountered this narrow plume. It would seem reasonable that the Lakeview G.S. was the source of this plume, though the use of default temporal profiles of emissions from major point sources in the model results in the specification of no emissions from Lakeview on weekends. The lack of emissions from Lakeview in the model on 24 August would explain the underprediction of $\mathrm{NO}_{2}$ by the model for regions downwind of the plant, though the model also underpredicts $\mathrm{NO}_{2}$ for a much larger area downwind of Toronto.

As was seen for 18 August, the model generally underpredicts the $\mathrm{NO}_{2}$ concentration for regions surrounding Toronto. Shortly after takeoff, while the aircraft is over and downwind of suburban areas to the east of Toronto, observations give $\mathrm{NO}_{2}$ concentrations of between 2 and $5 \mathrm{ppbv}$, though model predictions are less than $0.5 \mathrm{ppbv}$. Likewise, for times the aircraft passes over and downwind of Hamilton and other urbanized regions to the west of Toronto, the model consistently underpredicts the concentration of $\mathrm{NO}_{2}$.

\subsection{Thursday 29 August}

Of the three days studies, 29 August was the only weekday and was also the day with the strongest synoptic flow. Surface winds recorded at Toronto International Airport were from the northwest between 15 and $20 \mathrm{~km} \mathrm{~h}^{-1}$ during the afternoon. The model predicted surface winds agree well with these observations. There is no information on the depth of the boundary layer on this day as the aircraft did not fly higher than $1300 \mathrm{~m}$ a.s. 1 .

As shown in panel (A) of Fig. 4, the model predicts two distinct plumes over Lake Ontario. The plume from the city of Toronto is centered at approximately $79.3^{\circ} \mathrm{W}$, while a second plume, largely resulting from emissions from the Lakeview G.S., is shown centered just west of $79.5^{\circ} \mathrm{W}$. The Lakeview plume is evidenced by the aircraft observations, which sampled the plume at approximately 16:51, 17:01 and 17:24 EDT. Each of these encounters with the Lakeview plume are reproduced in the model data, though the peak $\mathrm{NO}_{2}$ concentration is significantly underpredicted.

In general, the model predicts the concentration of $\mathrm{NO}_{2}$ downwind of Toronto very well for 29 August. For the period of time when the aircraft was flying through the Toronto plume, which includes the plume from the Lakeshore G.S., the average predicted $\mathrm{NO}_{2}$ concentration is $12 \%$ lower than the observed average concentration of $\mathrm{NO}_{2}$. Similar to what was seen for the other two 
days of the study, model predictions of $\mathrm{NO}_{2}$ for regions outside of Toronto do not compare as favourably. The aircraft spent a considerable amount of time, from takeoff until 16:30 EDT, flying over urbanized regions to the east of Toronto. Observations during this portion of the flight show a considerable area with $\mathrm{NO}_{2}$ concentrations $>2 \mathrm{ppbv}$, with concentrations as high as $5 \mathrm{ppbv}$. Model predictions for this area give $<1 \mathrm{ppbv}$. Model predictions for the regions along the western end of Lake Ontario are also generally smaller than the observations.

\subsection{Discussion of $\mathrm{NO}_{2}$ results}

As expected, the measured concentrations of $\mathrm{NO}_{2}$ display considerably greater variability than the model calculations. However, when the aircraft and model concentrations are averaged for the time when the aircraft was judged to be within the Toronto plume, the model predictions and observations show good agreement for two of the three study days. These results suggest there are no significant errors in the inventory for $\mathrm{NO}_{x}$. However, the comparison for 24 August shows that the observed $\mathrm{NO}_{2}$ concentration in the Toronto plume is nearly a factor of three times larger than that calculated by the model.

The results for the simulation of $\mathrm{NO}_{2}$ downwind of Toronto on 24 August stand in contrast to the results for the other two days. The simulation of the meteorology for 24 August appears to be roughly in accord with observations. Certainly errors in either surface winds or boundary layer depth do not appear to be large enough to explain the factor of three difference between the model predicted and observed $\mathrm{NO}_{2}$ concentrations downwind of Toronto. In fact, it appears that the boundary layer depth over Toronto may be underestimated by the model, which would have had the effect of giving erroneously large $\mathrm{NO}_{2}$ concentrations. The inclusion of emissions from the Lakeview G.S. in the model simulation would have improved the model $\mathrm{NO}_{2}$ downwind of Lakeview, though the significant underprediction of $\mathrm{NO}_{2}$ from the city of Toronto itself would have remained.

One possible explanation for the poor agreement between the modelled and observed $\mathrm{NO}_{2}$ concentrations is the chemical conversion of $\mathrm{NO}_{2}$ to other species. As only observations of $\mathrm{NO}_{2}$ have been compared to model results, an incorrect partitioning of $\mathrm{NO}_{x}$ between $\mathrm{NO}$ and $\mathrm{NO}_{2}$ by the model may have led to errors in $\mathrm{NO}_{2}$. More importantly, errors in the conversion of $\mathrm{NO}_{x}$ to other nitrogen compounds may also have lead to errors in the model predicted $\mathrm{NO}_{2}$. Though measurements were made as close to Toronto as possible, some photochemical processing of the airmass will have occurred between the time of emission and the time of observations. Our model results predict that in the
Toronto plume between $20 \%$ and $30 \%$ of the $\mathrm{NO}_{x}$ has been converted to other nitrogen species before sampling by the aircraft. This amount of $\mathrm{NO}_{x}$ oxidation is too small to account for the large difference between the observed and modelled $\mathrm{NO}_{2}$ on 24 August and any systematic error in the chemistry of $\mathrm{NO}_{2}$ would also affect results for the two other study days. Airborne measurements of the sum of reactive nitrogen, $\mathrm{NO}_{y}$, would be required to provide the necessary observations to determine whether the model is actually converting $\mathrm{NO}_{x}$ to other species too rapidly. At this time, no explanation for the poor model performance for 24 August can be given, other than possible problems with the partitioning of emissions between different days of the week.

The second general feature of the comparison of predicted and observed $\mathrm{NO}_{2}$ concentrations is the widespread underprediction of $\mathrm{NO}_{2}$ concentrations by the model for times when the aircraft was over or downwind of urbanized regions surrounding Toronto. On each of the study days significant plumes of $\mathrm{NO}_{2}$ were observed in the vicinity of Hamilton, as well as downwind of other urbanized regions to the west of Toronto. In general, model calculations underpredicted the observed concentration of $\mathrm{NO}_{2}$ during these times, with very large underpredictions occurring when the aircraft encountered the putative Hamilton plume. Though the aircraft did not spend a great deal of time to the east of Toronto, observations show $\mathrm{NO}_{2}$ concentrations of between 2 and $5 \mathrm{ppbv}$, though the model rarely predicts concentrations $>1$ ppbv.

One likely cause for the repeated underprediction of $\mathrm{NO}_{2}$ over suburban regions outside of Toronto is the change in population distribution between 1985, the year for which the emission inventory is valid, and 1996, the year of the aircraft study. For example, census information shows that between 1991 and 1996 the population of the city of Toronto increased by $4.8 \%$, while suburban communities surrounding Toronto experienced increases of between $12 \%$ and $20 \%$ (Statistics Canada, 2000). The changing geographic distribution of population will have important implications for the assessment of trends in emissions from long-term surface observations at fixed sites.

\section{Non-methane hydrocarbon measurements}

Typically between 5 and 10 hydrocarbon samples were taken during both the upwind and downwind of Toronto flights. Analysis of the observations suggests that many of the samples taken during the downwind flight do not show hydrocarbon concentrations that are significantly greater than the observed upwind concentration. To simplify the analysis, only hydrocarbon samples taken while the aircraft was within the Toronto 
plume and which show total hydrocarbon concentrations (expressed as ppb Carbon) at least 50\% greater than the average upwind concentrations have been included in the following analysis. The selection criteria reduces the number of hydrocarbon samples from the downwind flights to six. Model calculated concentrations of $\mathrm{NO}_{x}$ at the time and position of the hydrocarbon sampling and the ratio of individual hydrocarbon species to $\mathrm{NO}_{x}$ are compared with observations in Fig. 5. Since observations of $\mathrm{NO}_{x}$ were not available, the observed $\mathrm{NO}_{2}$ concentration was scaled by the model calculated $\mathrm{NO}_{2} / \mathrm{NO}_{x}$ ratio to derive an observed $\mathrm{NO}_{x}$.

As was seen above, a large degree of scatter is seen in the comparison of spatially and temporally paired modelled and observed $\mathrm{NO}_{x}$ concentrations. However, with the exception of hydrocarbon sample (c), for times and locations where the hydrocarbon samples were taken, the model calculated $\mathrm{NO}_{x}$ concentration is within $\pm 50 \%$ of the observed concentration. To reduce the scatter when comparing the model and observations, the observed hydrocarbon concentrations have been ratioed to the observed $\mathrm{NO}_{x}$ concentration and this ratio has been compared with the comparable quantity derived from the model. Since we are primarily interested in emissions from Toronto, the concentration of the longer lived hydrocarbon species (propane, the lumped $\geqslant \mathrm{C}_{4}$ alkane species and toluene) have been corrected to account for the upwind concentrations, where the upwind concentration for each day has been defined as the average of the three upwind hydrocarbon samples with the smallest hydrocarbon concentration. The observed upwind of Toronto concentration was subtracted from both the modelled and observed downwind concentration before the hydrocarbon- $\mathrm{NO}_{x}$ ratios were calculated.

As can be seen in Fig. 5, there is some scatter present in the comparison of model calculations and observations, though general features of the comparison for the model hydrocarbon species are readily apparent. The comparison of model predictions and observations for the model propane (which includes benzene and acetylene) shows that the model always underpredicts the ratio of propane to $\mathrm{NO}_{x}$. These results suggest that emissions of the propane species are underpredicted by a factor of two in the inventory. The model generally overpredicts the concentration of the $\geqslant \mathrm{C}_{4}$ alkane, though accounting for the unobserved fraction of the $\geqslant \mathrm{C}_{4}$ alkane species, as discussed above, would bring the observations and model into better agreement. The comparison of observations and model predictions for the $\geqslant \mathrm{C}_{3}$ alkene to $\mathrm{NO}_{x}$ ratio shows a bias towards overprediction, suggesting the inventory may overestimate emissions of the $\geqslant \mathrm{C}_{3}$ alkene species. For
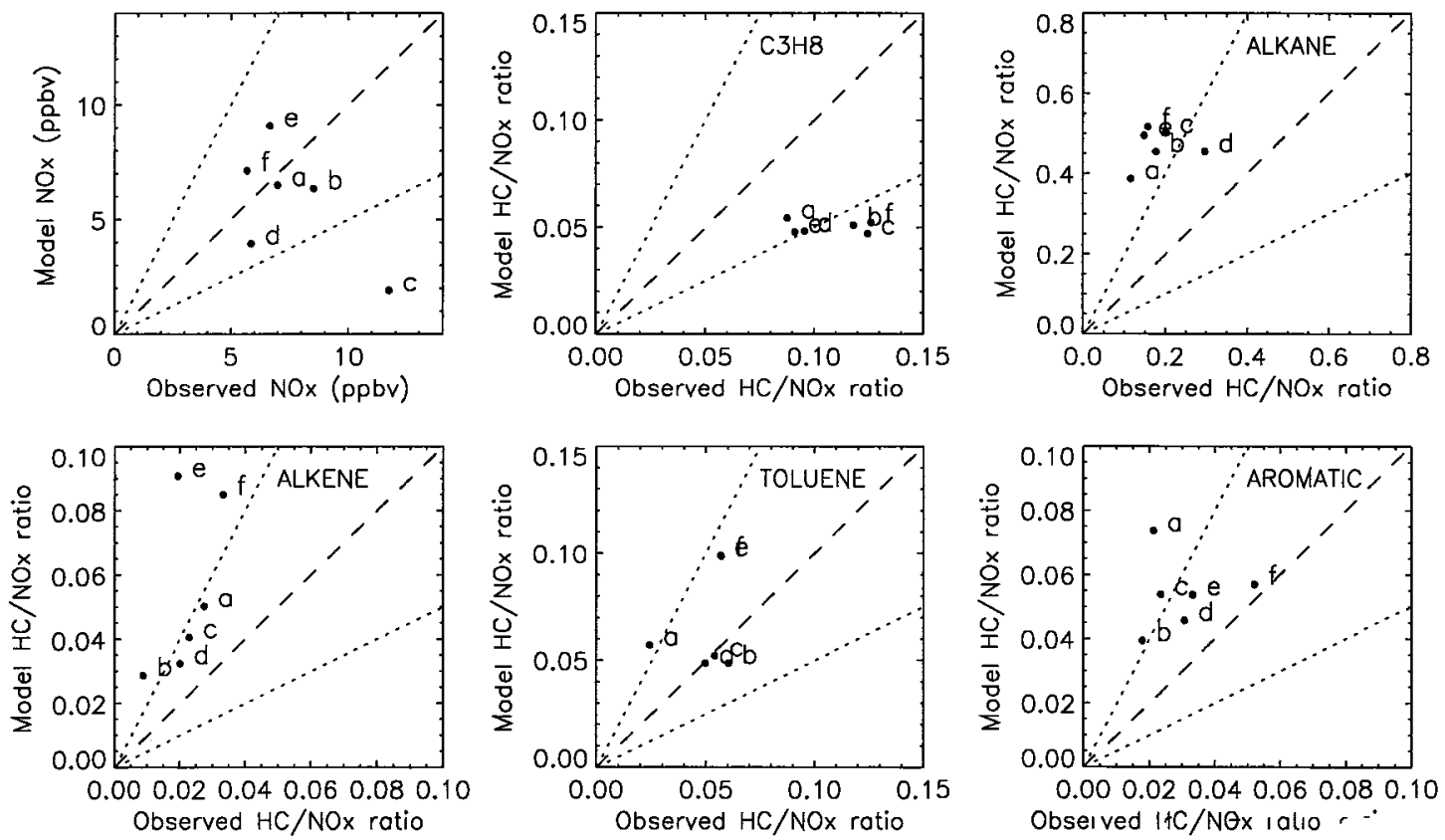

Fig. 5. A scatterplot of the observed and model calculated $\mathrm{NO}_{x}$ concentration and $\mathrm{NO}_{x}$-hydrocarbon ratios within the Toronto plume for all three days modelled. Each canister sample is identified with a letter: (a) sample 6, 18 August; (b) sample 2, 24 August; (c) sample 6, 24 August; (d) sample 7, 24 August; (e) sample 5, 29 August; (f) sample 6, 29 August. Model concentrations are derived by spatial and temporal interpolation of the model fields to the aircraft location at which the hydrocarbon sample was taken. 
toluene, despite a large degree of scatter, no significant bias in the model calculated concentration is found. For the lumped aromatic species, model calculations tend to overpredict the concentration, though there is likely a significant fraction of the model lumped aromatic species that was unobserved.

A comparison of modelled and observed ethene concentrations was not performed due to the use of ethene as a surrogate for methyl-vinyl ketone and methacrolein. The ADOM chemical mechanism, presumably to avoid the computational expense of additional chemical species, produces ethene from the reaction of $\mathrm{OH}$ with isoprene. Oxidation of isoprene is a significant artificial source of ethene in the model and confounds any comparison of modelled and observed concentrations. We do note that correlation of the observed ethene and $\mathrm{NO}_{x}$ concentrations yields a linear best-fit slope of $0.060 \pm 0.013$ moles of ethene per mole $\mathrm{NO}_{x}\left(r^{2}=0.83\right)$, which is smaller than the ethene- $\mathrm{NO}_{x}$ ratio found in the emissions inventory for Toronto of 0.089 .

\subsection{Discussion}

With the exception of the model propane species, the comparison of the modelled and observed hydrocarbon$\mathrm{NO}_{x}$ ratios strongly suggests that there are no significant underpredictions of the hydrocarbon emissions in the inventory. In fact, for several species the model showed a bias towards overpredicting the hydrocarbon- $\mathrm{NO}_{x}$ ratio in the Toronto plume, though accounting for unmeasured hydrocarbon species would act to reduce this bias.

As discussed above for $\mathrm{NO}_{x}$, uncertainties in the comparison of modelled and observed concentrations include errors in the model representation of dispersion and photochemical removal. Backtrajectory analysis suggests that for the three study days, air parcels traversed the Toronto region and were sampled by the aircraft in approximately $2 \mathrm{~h}$. Calculating losses of hydrocarbons by reaction with $\mathrm{OH}$ and $\mathrm{O}_{3}$, assuming an $\mathrm{OH}$ concentration of $1.0 \times 10^{7}$ molecules $\mathrm{cm}^{-3}$ and an $\mathrm{O}_{3}$ concentration of $50 \mathrm{ppbv}$, shows that losses for some of the more reactive hydrocarbon species can be quite significant. For the $\geqslant \mathrm{C}_{3}$ alkene species, approximately $65 \%$ of the total amount emitted into the airmass will have undergone initial oxidation by the time the airmass is sampled by the aircraft. Loss of the lumped aromatic species is estimated to be approximately $50 \%$, while photochemical removal for the remaining hydrocarbon species is estimated to be $<25 \%$. Though the model will account for oxidation of hydrocarbon species, the large fraction of the lumped alkene and aromatic species removed by oxidation introduces significant uncertainties into the comparisons for these two species.

\section{Conclusions}

An aircraft-based measurement campaign was conducted during the summer of 1996 in the vicinity of Toronto, Canada. Measurements of $\mathrm{NO}_{2}$ and hydrocarbons were made upwind and downwind of Toronto on days with strong synoptic-scale flow from a west to northerly direction. By quantifying the chemical composition of the airmass before and after it passed over Toronto, and comparing these observations with output from a three-dimensional online air quality model, we have attempted to verify the emissions data used in the model. Although differences between the modelled and observed $\mathrm{NO}_{2}$ concentration can be quite large at any one location, averaged over the time the aircraft was believed to be within the Toronto plume, the observations and model calculations give good agreement for $\mathrm{NO}_{2}$ on two of the three days studied. The model predicted $\mathrm{NO}_{2}$ concentration is within $12 \%$ of the observed concentration for both of these days. For the remaining day of the study, observations show average $\mathrm{NO}_{2}$ concentrations in the Toronto plume that were nearly a factor of three higher than the model calculations. The high level of agreement for two of the three days studied suggests that the anthropogenic $\mathrm{NO}_{x}$ emissions used in the model are reasonably accurate, though the unexplained poor predictions for the third day are troublesome.

For regions outside Toronto, particularly over and downwind of the urban and suburban regions to the east and west of Toronto, the observed $\mathrm{NO}_{2}$ concentration is seriously underpredicted by the model for all three days which have been modelled. Given the consistency with which the model $\mathrm{NO}_{2}$ concentration is underpredicted, it seems plausible to suggest that the emissions inventories underpredict $\mathrm{NO}_{x}$ emissions for these regions. A likely reason for the underprediction of $\mathrm{NO}_{x}$ emissions is the significant increase in population which has occurred in the suburban areas surrounding Toronto between 1985 , the base year of the emissions inventory, and 1996.

The emissions of hydrocarbons have also been investigated by comparing modelled and observed ratios of hydrocarbon species to $\mathrm{NO}_{x}$ for the Toronto plume. These comparisons suggest that emissions of the model propane species, which includes benzene and acetylene, are underestimated by approximately a factor of two in the emissions data. The emissions of other hydrocarbon species do not show any evidence of a significant bias. There is certainly no evidence for a factor of two or larger underprediction for hydrocarbon emissions, as has been previously reported for other locales.

Uncertainties in the present analysis include errors in the model representation of the meteorology, photochemical loss of $\mathrm{NO}_{x}$ and some of the more reactive hydrocarbon species during transport across Toronto and the contribution of unmeasured hydrocarbon 
species to the total hydrocarbon concentration. These uncertainties could be reduced by including a larger number of days in the study and using observations of the total reactive nitrogen, $\mathrm{NO}_{y}$, as opposed to $\mathrm{NO}_{2}$.

A further refinement of the work presented here would be to use a version of the emissions inventory with greater speciation, together with a modified chemical mechanism. A more detailed emissions inventory would reduce some of the uncertainty when comparing model and observed concentrations of hydrocarbon species for which the measurements capture only a fraction of all the species included in the model lumped hydrocarbon species.

\section{Acknowledgements}

We would like to thank B. Fu, S. Fong, A. Fogel and D. Schiff for their help during the field campaign and $R$. Laprise at the Universite du Quebec a Montreal for his contribution to the development, and advice on the use of, the MC2 model. J.C. McConnell wishes to thank Environment Canada and the Natural Sciences and Engineering Research Council (NSERC) for continuing support. The authors would like to thank the Canadian Institute for Research in Atmospheric Chemistry (CIR$A C)$, its members and their representatives, particularly the Ontario Ministry of the Environment and the Ontario Region Office of the Meteorological Service of Canada, for financial support. Additional financial support for this study was provided by NSERC.

\section{References}

Benoit, R., Desgagné, M., Pellerin, P., Pellerin, S., Chartier, Y., Desjardins, S., 1997. The Canadian MC2: a semi-Lagrangian semi-implicit wideband atmospheric model suited for finescale process studies and simulations. Monthly Weather Review 125, 2382-2415.

Ching, J.K.S., Novak, J.H., Schere, K.L., 1987. Reconciling urban $\mathrm{VOC} / \mathrm{NO}_{x}$ emission inventories with ambient concentration data. Paper No. 87-58.3, Presented at the Air Pollution and Control Association 80th Annual Meeting, New York.

Drummond, J.W., Castledine, C., Green, J., Denno, R., Mackay, G.I., Schiff, H.I., 1990. In: Zielinski Jr., E.W.L., (Ed.), New Technologies for use in Acid Deposition
Networks, in Monitoring Methods for Toxics in the Atmosphere, Report ASTM STP 1052. American Society for Testing and Materials, Philadelphia, PA.

Fujita, E.M., Croes, B.E., Bennett, C.L., Lawson, D.R., Lurmann, F.W., Main, H.H., 1992. Comparison of emission and ambient concentration ratios of $\mathrm{CO}, \mathrm{NO}_{x}$ and NMOG in California's South Coast Air Basin. Journal of Air and Waste Management Association 42, 264-276.

Lewis, A.C., Carslaw, N., Marriott, P.J., Kinghorn, R.M., Morrison, P., Lee, A.L., Bartle, K.D., Pilling, M.J., 2000. A larger pool of ozone-forming carbon compounds in urban atmospheres. Nature 405, 778-781.

Middleton, P., Stockwell, W.R., Carter, W.P., 1990. Aggregation and analysis of volatile organic compound emissions for regional modelling. Atmospheric Environment 24, 1107-1133.

$\mathrm{NO}_{x} /$ VOC-SP (Multi-stakeholder $\mathrm{NO}_{x} /$ VOC Science Program), 1997. Modelling of ground-level ozone in the WindsorQubéc City corridor and in the southern Atlantic region. Canadian $1996 \mathrm{NO}_{x} /$ VOC Science Assessment, Report ISBN 1-896997-06-6.

Oke, T.R., 1982. The energetic basis of the urban heat island. Quarterly Journal of the Royal Meteorological Society 108, $1-24$.

Pierson, W.R., Gertler, A.W., Bradow, R.L., 1990. Comparison of the SCAQS tunnel study with other on road vehicle emission data. Journal of Air and Waste Management Association 40, 1495-1504.

Pierson, W.R., Gertler, A.W., Robinson, N.F., Sagebiel, J.C., Zielinska, B., Bishop, G.A., Stedman, D.H., Zweidinger, R.B., Ray, W.D., 1996. Real-world automotive emissionsSummary of studies in the Fort McHenry and Tuscarora Mountain tunnels. Atmospheric Environment 30, 2233-2256.

Plummer, D.A., 1999. On-line Chemistry in a Mesoscale Model: Assessment of the Toronto Emission Inventory and Lake-Breeze Effects on Air Quality. Ph.D. Thesis, York University, Toronto, Canada, 281pp.

Statistics Canada, 2000. Adopted from the Statistics Canada Internet Site, http://CEPS. statcan. ca/english/profil/PlaceSearchForm1.cfm.

Trainer, M., Ridley, B.A., Buhr, M.P., Kok, G., Walega, J., Hübler, G.H., Parrish, D.D., Fehsenfeld, F.C., 1995. Regional ozone and urban plumes in the Southeastern United States: Birmingham, a case study. Journal of Geophysical Research 100, 18823-18834.

US EPA (United States Environmental Protection Agency), 1989. The 1985 NAPAP emission inventory (version 2). In: Development of the Annual Data and Modelers Tapes. Report EPA-600/7-89-012a, National Tech. Info. Serv., Springfield, VA., 692pp. 